\title{
The Effect of Vacuum Degree on the Porosity and Mechanical Properties of Die Cast $\mathrm{AlSi}_{9} \mathrm{Cu}_{3}(\mathrm{Fe})$ Alloy
}

\author{
Péter Szalva ${ }^{1^{*}}$ and Imre Norbert Orbulov ${ }^{1,2}$ \\ ${ }^{1}$ Department of Materials Science and Engineering, BME, Müegyetem rakpart 3., Budapest, 1111, Hungary \\ ${ }^{2}$ MTA-BME Lendület Composite Metal Foams Research Group, BME, Müegyetem rakpart 3., Budapest, 1111, Hungary
}

Received: 22 June 2018; accepted: 03 November 2018

\begin{abstract}
$\mathrm{AlSi}_{9} \mathrm{Cu}_{3}(\mathrm{Fe})$ aluminum alloy specimens were produced by conventional high-pressure die casting (HPDC) and vacuum-assisted high-pressure die casting (VPDC) processes under atmospheric and 3 different absolute pressures of 170 mbar, 90 mbar, and 70 mbar. The influence of absolute pressure in the die cavity on the porosity and mechanical properties of the die castings were investigated and compared with the traditional casting method. The life data analysis was applied to deal with the variation in mechanical properties of the die cast flat tensile specimens. The porosity of castings was assessed on the basis of X-ray observation and density measurements performed by Archimedes method. The fracture surfaces were examined by scanning electron microscopy (SEM), and the chemical composition was measured by energy dispersive X-ray analysis (EDX). The investigations proved that the volume of gas porosity and the pore sizes in the castings can be significantly reduced by using vacuum assistance during the die casting process. Based on the data presented in the study, the porosity reduced from $1.10 \%$ at an atmospheric level to $0.47 \%$ at 70 mbar, which corresponds to $57 \%$ reduction. The boundary condition of the present investigation is the porosity content higher than $0.40 \%$ and lower than $1.10 \%$. As a result, the density and the mechanical properties, particularly the tensile strength $(10 \%)$ and elongation $(50 \%)$ were significantly improved. The specimens contained smaller pores under lower pressure. Meanwhile, the shape of pores is found to be also an important factor, affecting the mechanical properties. In general, higher vacuum degree contributes to the reduction the porosity, which would be the basis to improve the mechanical properties of die cast parts.
\end{abstract}

Keywords: vacuum-assisted HPDC, mechanical properties, porosity, Weibull analysis, Hydrostatic weighing, SEM

\section{Introduction}

In the automotive industry, the environment protection is becoming a more and more important factor not just during the production, but even during the operation too. Therefore, light-metal alloys and mainly the aluminum alloys are the optimum choice for part manufacture [1], where they offer significant advantages of lightweight, attractive appearance, excellent processability and high corrosion resistance besides it complete recyclability. The automotive market for lightmetal shapes continues to grow at an increasing rate. In particular, the aluminum-silicon (Al-Si) and aluminum-siliconcopper $(\mathrm{Al}-\mathrm{Si}-\mathrm{Cu})$ cast alloys are widely used in different application fields because of their good castability.

High-pressure die casting (HPDC) technology is a near-net shape manufacturing process in which molten metal is injected into a metal mold at high speeds [2] and allowed to solidify under high pressure. The HPDC technology is a suitable method for the production of aluminum and low-melting alloy castings [3], which provide good quality of products, high surface smoothness, and excellent dimensional and shape accuracy, accompanied by the relatively low production costs. The applications of aluminum die castings are normally (but not totally) limited to non-structural components that do not require such a heat treatment or welding. Porosity causes more rejected castings than any other factor.

In cold-chamber die casting of aluminum alloys, air and other gases are often trapped in the metal [4], because of the turbulence of the alloy as it is forced into the die cavity at a high pressure and speed. This phenomenon can result in pores in the casting, which may affect the mechanical properties of the product [5]. In structural applications, it can act as a stress

\footnotetext{
*Author for correspondence: szalva@eik.bme.hu.
}

concentrator and, therefore, create a site where cracks may occur. An additional problem is the fact that the porosity of a casting may not always be immediately apparent. If discovered after subsequent secondary processing, customer dissatisfaction can be extreme. One possible solution is vacuum assistance [6]. Attempts to develop methods of vacuumassisted die casting were introduced into cold-chamber die casting machines. This use of vacuum in the die casting process is an innovative development.

Before the injection shot occurs, a vacuum is drawn in both the shot sleeve and the mold cavity [7]. The vacuum is maintained until the injection cycle is completed. Almost all of the air and other gases are evacuated from the mold. A sufficient vacuum in the mold cavity enables the alloy to flow into blind recesses in complex shapes. It also allows the fronts of the molten metal to merge freely without forming shuts. These observations are typical of much work carried out on the filling of the die during the injection of pressure die castings [8].

The aim of the present work is to investigate the effect of the vacuum-assisted method on the mechanical properties of the cast by life data analysis, which is known as the Weibull analysis [9]. A two-parameter Weibull distribution model was applied to deal with the variation in mechanical properties.

\section{Experimental Details}

The experiments were performed on an $\mathrm{AlSi}_{9} \mathrm{Cu}_{3}(\mathrm{Fe})(\mathrm{EN}$ AC 46000 or DIN 226) casting aluminum alloy, and its nominal chemical composition is detailed in Table 1. This kind of aluminum alloy is widely used and a relatively cheap casting material, but has not been extensively examined from vacuumassisted HPDC point of view. Another reason for choosing this aluminum grade is the favorable strength properties due to its relatively high copper content. This casting material is preferred mainly for structural components in the automotive industry. 
Table 1. Chemical composition of $\mathrm{AlSi}_{9} \mathrm{Cu}_{3}(\mathrm{Fe})$ [10]

\begin{tabular}{lcccccccc}
\hline Alloy & $\mathrm{Si}(\mathrm{wt} \%)$ & $\mathrm{Fe}(\mathrm{wt} \%)$ & $\mathrm{Cu}(\mathrm{wt} \%)$ & $\mathrm{Mn}(\mathrm{wt} \%)$ & $\mathrm{Mg}(\mathrm{wt} \%)$ & $\mathrm{Zn}(\mathrm{wt} \%)$ & $\mathrm{Ti}(\mathrm{wt} \%)$ & $\mathrm{Residue}$ \\
\hline $\mathrm{AlSi}_{9} \mathrm{Cu}_{3}(\mathrm{Fe})$ & $9-11$ & $0.6-1$ & $2.2-3.5$ & $0.25-0.4$ & $0.25-0.5$ & $0.4-1$ & 0.08 & $\mathrm{Al}$ \\
\hline
\end{tabular}

Casting test specimens were produced using a horizontal cold-chamber die casting machine OMS 450. The machine was equipped with a vacuum system consisting of a vacuum pump and vacuum valves, in order to evacuate the air and other gases $[5,6]$, which are entrapped in the mold cavity and in the injection sleeve system. The vacuum system was connected directly to the die tool's venting system. The vacuum valve was located in the top of the die tool, preventing the flow of metal into the vacuum system. The adjusted pressure was atmospheric in the case of conventional HPDC and 3 different absolute pressures of 170 mbar, 90 mbar, and 70 mbar in the case of VPDC. The examinations were performed at the following constant technological parameters: a molten metal temperature of $680{ }^{\circ} \mathrm{C}$, a die temperature of $160-180{ }^{\circ} \mathrm{C}$, a total volume of casting gating and venting system of $289.3 \mathrm{~cm}^{3}$, a plunger diameter of $60 \mathrm{~mm}$, a plunger velocity during the first stage of $0.5 \mathrm{~m} / \mathrm{s}$ and during the second stage of $2.8 \mathrm{~m} / \mathrm{s}$, a multiplication pressure of $250 \mathrm{bar}$, and a clamping force of $3800 \mathrm{kN}$. The specimens were tested in 'T1' condition, which means controlled cooling of casting and naturally aged. The test was performed 8 days after casting, which guarantees the natural aging condition for the specimens.

The tensile strength of castings was determined using an Instron 5985 testing machine (Figure 1) with an extensometer gauge length of $L_{0}=50 \mathrm{~mm}$ at room temperature. The applied tensile rate was $1 \mathrm{~mm} / \mathrm{min}$.

The mechanical properties were measured on standard flat tensile specimens. The results were evaluated according to the standard ISO 6892-1:2016 [11], method B, specimen class D ( $a \geq 3 \mathrm{~mm}$ ), $5 \mathrm{~mm} \times 13 \mathrm{~mm}$ cross section (Figure 2).

The corners of the flat test piece act as stress concentrators against the round cross-section homogeneous stress distribution. The reason for using the flat specimen is the special features of casting technology, easier tool design, easier handling in the case of tool opening at overload. The cross-section has rounded corners of $0.2 \mathrm{~mm}$, and the draft was taken into account at the cross section calculation.

The porosity of castings was assessed by the BN-75/405110 standard [12]. Hydrostatic weighing was carried out [13]. Based on the standard procedure [14], all specimens were weighted in air and in water, respectively, and their densities were determined according to the following equation [15]:

$$
\rho_{s}=\frac{m_{1}}{m_{1}-m_{2}} \rho_{w}
$$

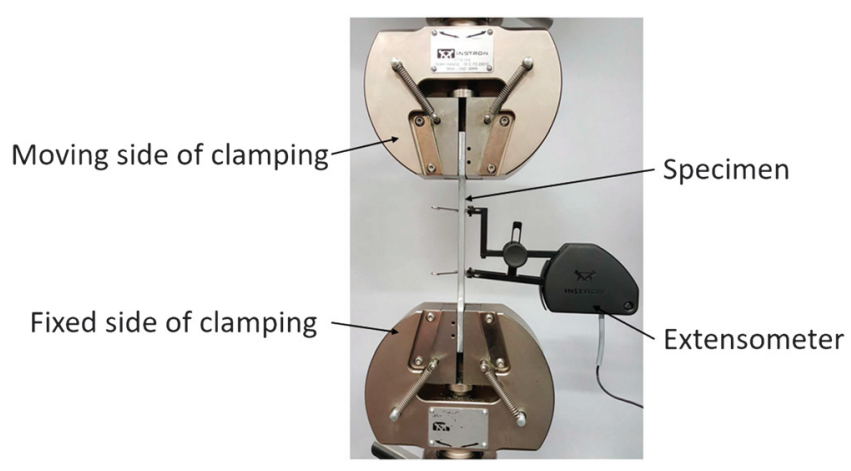

Figure 1. Test environment of the tensile test where $\rho_{\mathrm{s}}$ is the density of the specimen $\left(\mathrm{g} / \mathrm{cm}^{3}\right), \rho_{\mathrm{w}}$ is the density of water $\left(\mathrm{g} / \mathrm{cm}^{3}\right), m_{1}$ is the mass of the specimen $(\mathrm{g})$ in the air, and $m_{2}$ is the mass of the specimen $(\mathrm{g})$ in water.

The given density of specimen is taken into account for the porosity. The porosity of the examined specimens were calculated to the following equation:

$$
P=\left(1-\frac{\rho_{s}}{\rho_{A l}}\right) 100 \%
$$

where $P$ is the porosity (\%), $\rho_{\mathrm{s}}$ is the density of the specimen $\left(\mathrm{g} / \mathrm{cm}^{3}\right), \rho_{\mathrm{Al}}$ is the true density of EN AC $46000\left(2.75 \mathrm{~g} / \mathrm{cm}^{3}\right)$ according to EN1706 [16], and $\rho_{\mathrm{w}}$ is the density of water at $20^{\circ} \mathrm{C}$ $\left(0.998 \mathrm{~g} / \mathrm{cm}^{3}\right)$ according to ITS-90 [17].

The specimens were inspected by X-ray analysis before the uniaxial tensile test. Porosity [18] and shrinkage [19] were inspected according to ASTM E505 [20]. X-ray inspection [21] as a non-destructive testing is one of the best testing methods to investigate the porosity, cold fill, shrinkage, and foreign material content of the castings. According to the highest measure of the pores and shrinkage, considering sample thicknesses, the results were Level 1 due to vacuum assist. The detectable minimum error size has set the limits on the qualitative evaluation. Therefore, the results were used for pre-assessment for inclusion, shrinkage, and porosity control. Cold fills and foreign materials were not detected. Because of the nature of aluminum oxide, it cannot be detected in the casting by X-ray. The samples, which contain aluminum oxide [22] on the fracture surface, have been excluded from the evaluation. The porosity was examined on a Yxlon MU2000 $\mathrm{X}$-ray machine. The fracture surface was examined by an optical microscope (AM7915 Mzt by Dino-Lite) and by a scanning electron microscopy (SEM) [23] (Zeiss Sigma) equipped with an energy dispersive X-ray analyzer (EDX) [24].

Unfortunately, the properties of the material are not accurately reproducible [9]. Scatter of tensile properties has been a particular problem with castings. If the test bar fells below the strength value required by the specification, the standards normally allow a re-test, and the failed result is discarded. The common approach to deal with scatter is simply by taking the average, where the standard deviation might also be calculated. If we retain all results instead, 'good' and 'bad', and

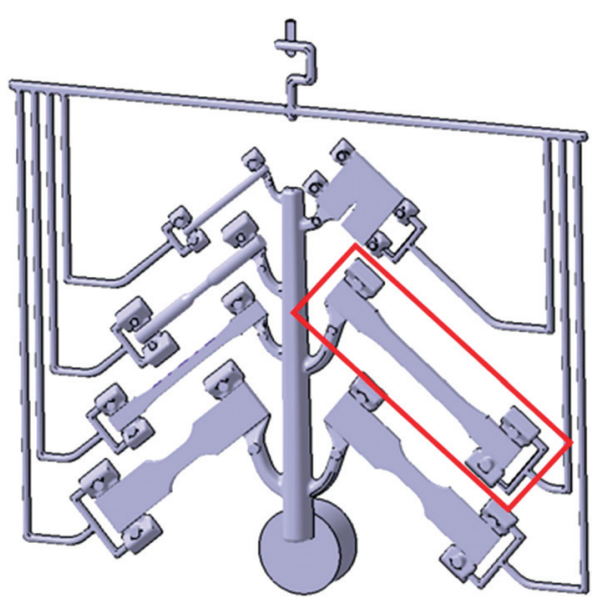

Figure 2. Casting bunch and the location of the investigated flat specimen 
Cumulative Distribution of Strength

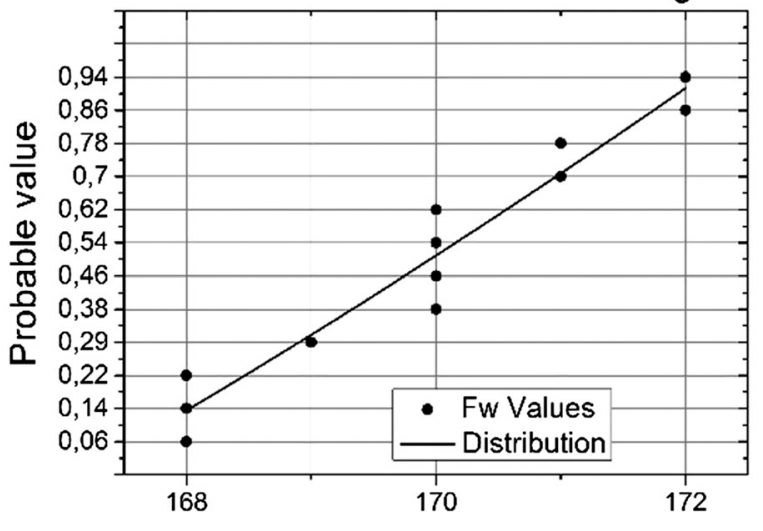

a) Proof Strength $R_{\mathrm{p} 0,2}(\mathrm{MPa})$ - at $70 \mathrm{mbar}$

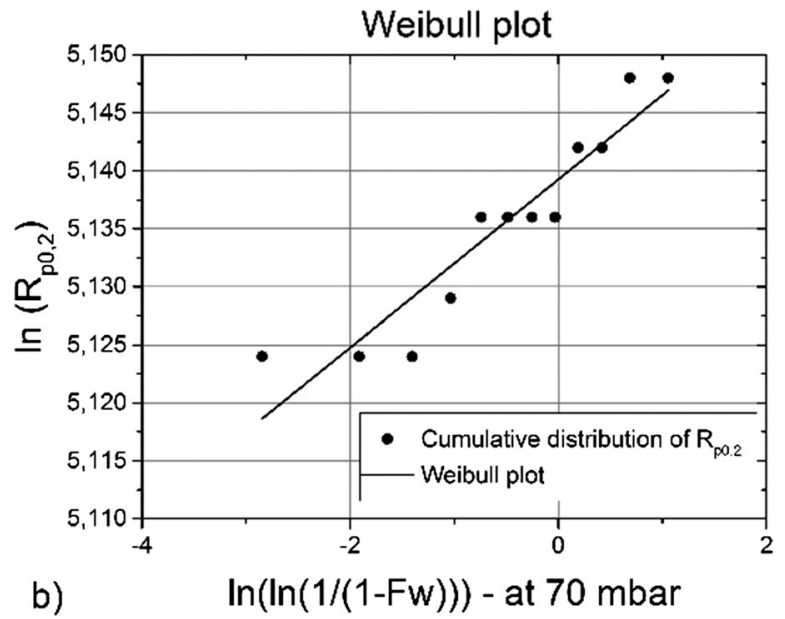

b)

Figure 3. (a) Cumulative distribution of strength and (b) Weibull plot of the data

plot them to reveal their cumulative distribution (CD), we can obtain a curve such as that in Figure 3a.

The shape of the distribution curve is usually not the symmetrical Gaussian form but is skewed in Figure 3b. The $F_{\mathrm{w}}$ values are meaning the median rank [25], and the median rank has no dimension. The $F_{\mathrm{w}}$ determined according to the following equation:

$$
F_{w}=\frac{i-0.3}{N+0.4}
$$

where $F_{\mathrm{w}}$ is the median rank, $i$ is the 'th' specimen, and $N$ is the total number of the specimen.

A close approximation to the shape of the curve was derived theoretically by Weibull [9]. The life data analysis, known as the Weibull plot, is another way of presenting a cumulative distribution of data.

The slopes of the Weibull plots are a measure of the reproducibility of the data, and are known as the Weibull modulus.

Figure 4 shows data for a single alloy but vacuum-assisted in a variety of pressure, showing the variation in reproducibility between different pressures. This kind of data is one of the simplest demonstrations of the importance of vacuumassistance on the reliability of cast products. Several slopes can sometimes be distinguished from the lowest to the highest results, corresponding to pores [26] and new bifilms [27]. The identification of the regimes of the strength of each of these

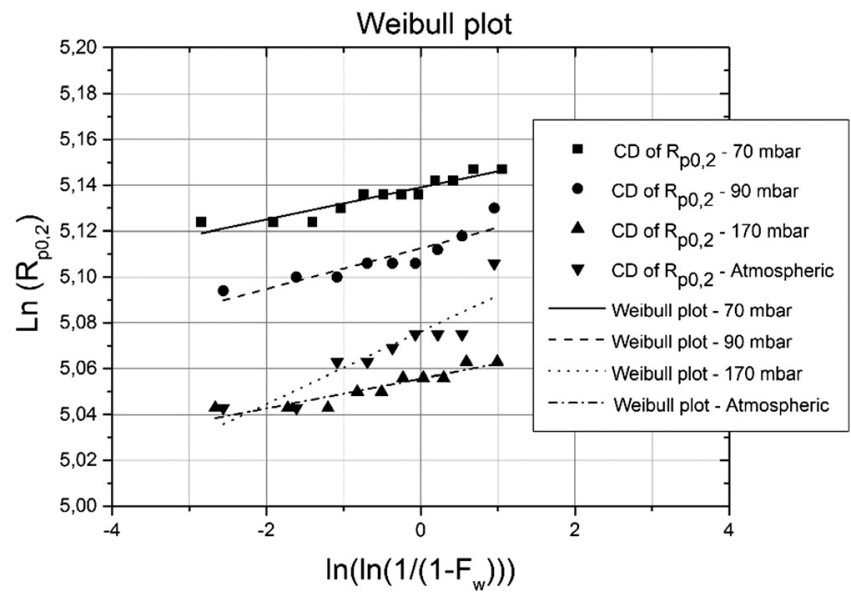

Figure 4. Weibull plot of proof strength $R_{\mathrm{p} 0.2}$ for $\mathrm{AlSi}_{9} \mathrm{Cu}_{3}(\mathrm{Fe})$ alloy in various vacuum assists defect types can give a valuable insight into the causes of poor performance.

\section{Results and Discussion}

$\mathrm{AlSi}_{9} \mathrm{Cu}_{3}(\mathrm{Fe})$ aluminum alloy castings were produced by a conventional HPDC process under atmospheric pressure and VPDC processes under 3 different absolute pressures of 170 mbar, 90 mbar, and 70 mbar. Twenty pieces of casting specimen were examined at each pressure level by X-ray method. The part quality based on the ASTM E505 was Level 1, which means a good result. Therefore, 15 random pieces were chosen for the evaluation. It was found that the gas porosity in the castings was not eliminated perfectly even with the vacuum assistance, but the volume of gas porosity was significantly reduced [28]. The detectable minimum error size was $0.2(\mathrm{~mm})$, which sets the lower limit on the qualitative evaluation [29]. The X-ray investigation was capable to find large pores. However, the method has a limit, namely, the minimum size of the detectable porosity. In the investigated castings, the pores were typically smaller than this limit. Therefore, SEM investigations were applied on the fracture surface to prove the presence of pores.

The densities of the castings were measured by Hydrostatic weighing, and the HPDC and VPDC specimens were compared. The results of the measurements are detailed in Table 2. The effect of vacuum assistance on the porosity shows a homogeneous distribution.

The specimen porosity and pressure curves show a significant change in the slope at around 70-90 mbar.

The effect of the vacuum-assistance on the mechanical properties is detailed in Table 3 at $50 \%$ reliability and in

Table 2. Pressure levels and porosity by averaging

\begin{tabular}{lc}
\hline Pressure (mbar) & Porosity by averaging (\%) \\
\hline 70 & 0.47 \\
90 & 0.67 \\
170 & 0.71 \\
Atmospheric & 1.10
\end{tabular}

The results were plotted as porosity versus pressure diagram (Figure 5).

Table 3. Mechanical properties of the $\mathrm{AlSi}_{9} \mathrm{Cu}_{3}(\mathrm{Fe})$ on different pressure levels at $50 \%$ reliability

\begin{tabular}{lccc}
\hline Pressure (mbar) & $R_{\mathrm{p} 0.2}(\mathrm{MPa})$ & $R_{\mathrm{m}}(\mathrm{MPa})$ & $A(\%)$ \\
\hline 70 & 170.3 & 299.8 & 2.49 \\
90 & 165.6 & 292.2 & 2.16 \\
170 & 156.5 & 283.9 & 2.14 \\
Atmospheric & 159.2 & 271.6 & 1.66 \\
Atm. (EN1706) & 140 & 240 & $<1$ \\
\hline
\end{tabular}


Table 4. Mechanical properties of the $\mathrm{AlSi}_{9} \mathrm{Cu}_{3}(\mathrm{Fe})$ on different pressure levels at $95 \%$ reliability

\begin{tabular}{lccc}
\hline Pressure (mbar) & $R_{\mathrm{p} 0.2}(\mathrm{MPa})$ & $R_{\mathrm{m}}(\mathrm{MPa})$ & $A(\%)$ \\
\hline 70 & 167.2 & 291.6 & 2.04 \\
90 & 161.7 & 276.3 & 1.63 \\
170 & 154.0 & 258.4 & 1.43 \\
Atmospheric & 152.9 & 253.7 & 1.31 \\
Atm. (EN1706) & 140 & 240 & $<1$ \\
\hline
\end{tabular}

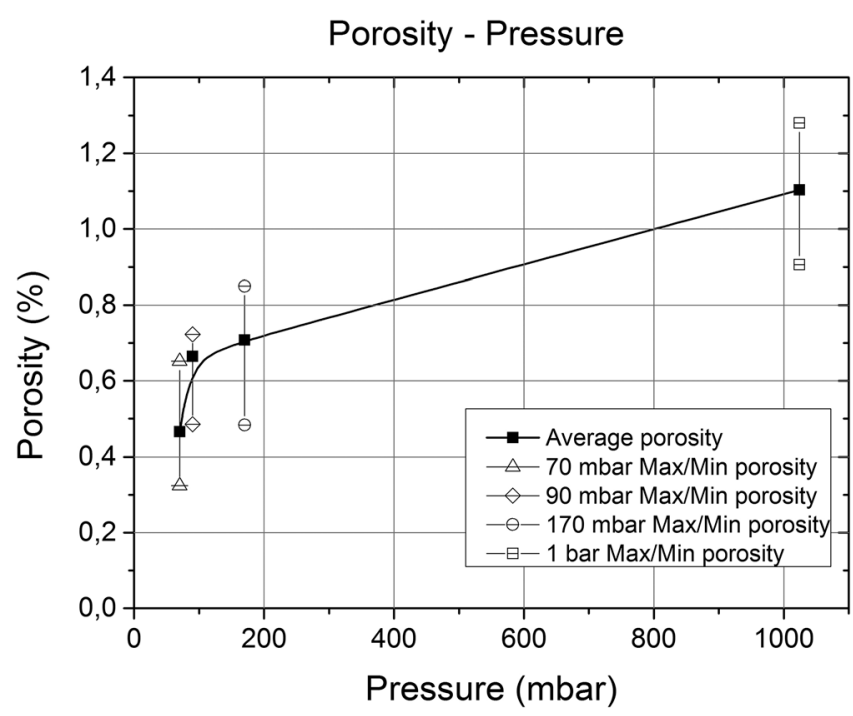

Figure 5. Specimen volumetric porosity-pressure curves

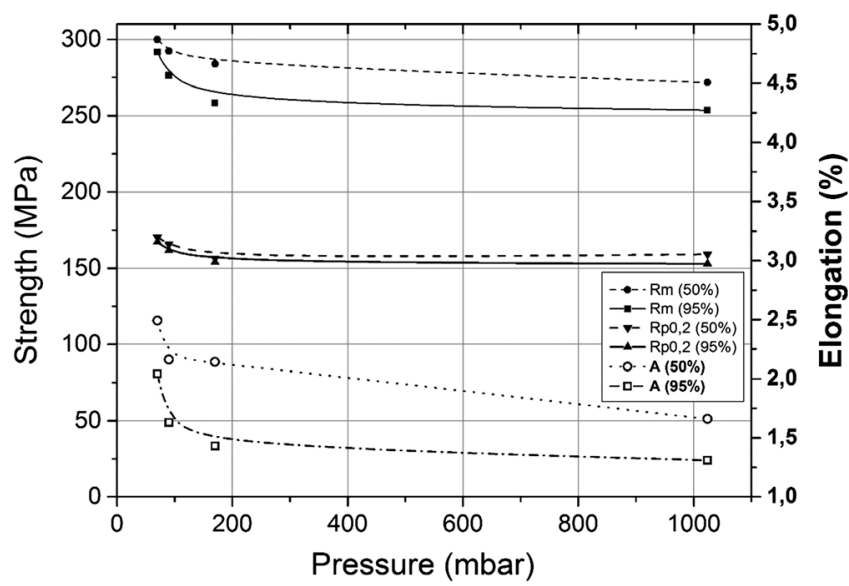

Figure 6. Mechanical properties on different reliability and pressure curves
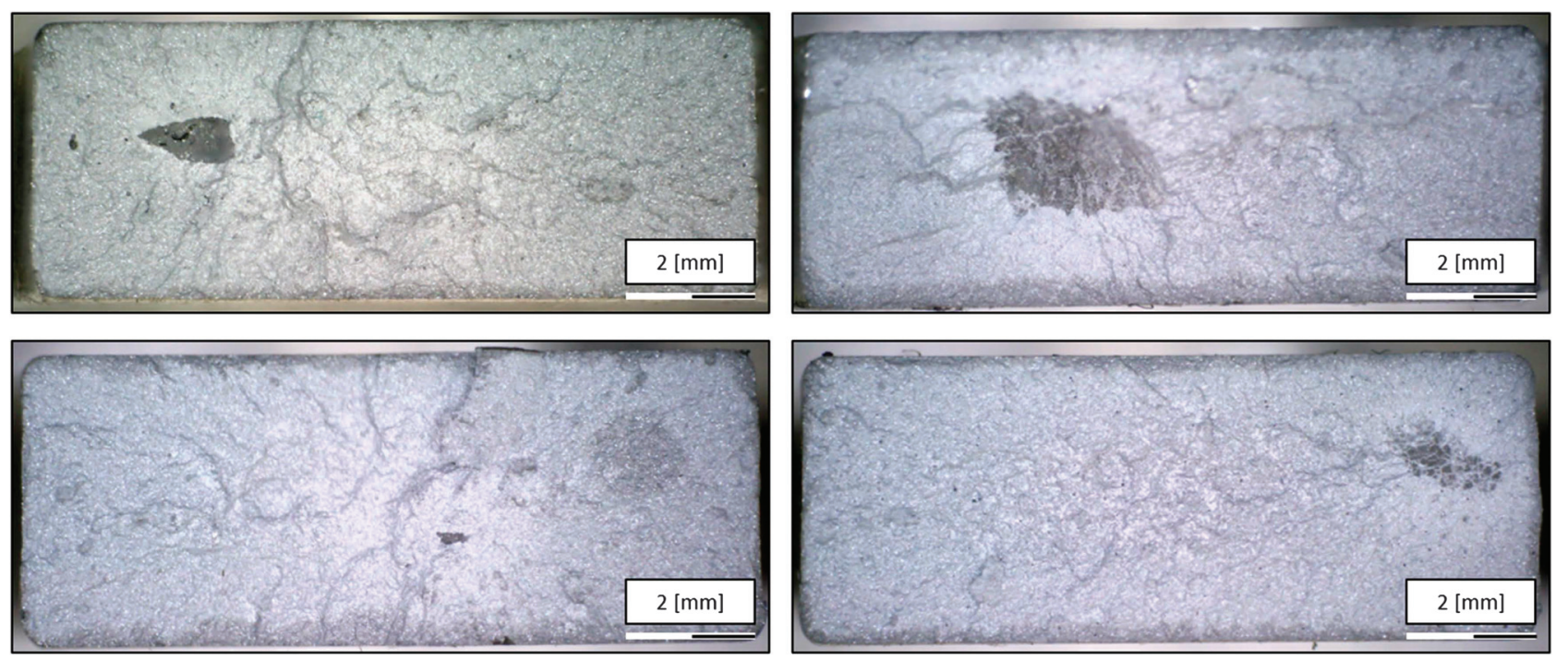

Table 4 at $95 \%$ reliability. The two-parameter Weibull distribution model [30] was applied to deal with the $50 \%$ and $95 \%$ reliability values on different pressure levels of the die cast. The main mechanical properties [31] investigated were the proof strength $R_{\mathrm{p} 0.2}$, the ultimate tensile strength $R_{\mathrm{m}}$, and the elongation $A$.

The life data analysis was applied to deal with the variation in the mechanical properties of the die cast flat tensile specimens. The values for the same pressure level did show significant deviation for the ultimate tensile strength and elongation, while the proof strength values were almost the same. The results were plotted in a diagram, showing the mechanical properties against the pressure (Figure 6).

The reason for the low deviation of the proof strength compared to the $50 \%$ and $95 \%$ reliability levels is the low scatter of the values. The strength curves are showing a remarkable change of the slope at around 70-90 mbar, which is similar than in the case of the porosity-pressure plot (Figure 5).

The samples, which contain aluminum oxide on the fracture surface, have been excluded from the evaluation [32]. The nature of aluminum oxide is quite the same, as aluminum alloy depends from the age of the oxide [33], and thin layer shape does not decrease the intensity of the radiation [34], which passes through the material. The aluminum oxide film or flakes act as stress concentrators $[35,36]$, which is why these samples have been excluded. The fracture surface was examined by optical microscopy (Figure 7) and scanning electron microscopy (SEM, Figure 8).

The energy dispersive X-ray (EDX) analysis verified the high aluminum oxide content on the fracture surface.

The boundary condition of the present investigation is the porosity content higher than $0.40 \%$ and lower than $1.10 \%$. I will plan to examine further pressure level to make sure that these changes on porosity content and on the mechanical properties have the same tendency on the slope of the curves at lower pressures. The lowest pressure level is theoretically at 50 mbar with the use of vacuum valve. However, maintaining this pressure in the used die tool cavity is not yet secured. If zero pressure can be achieved, the porosity will not even drop to zero, because the dissolved gas content of the liquid also appears in this case even more than zero. The pores as shrinkage cavities are still present.

Figure 7. Aluminum oxide flakes in the fracture surfaces 

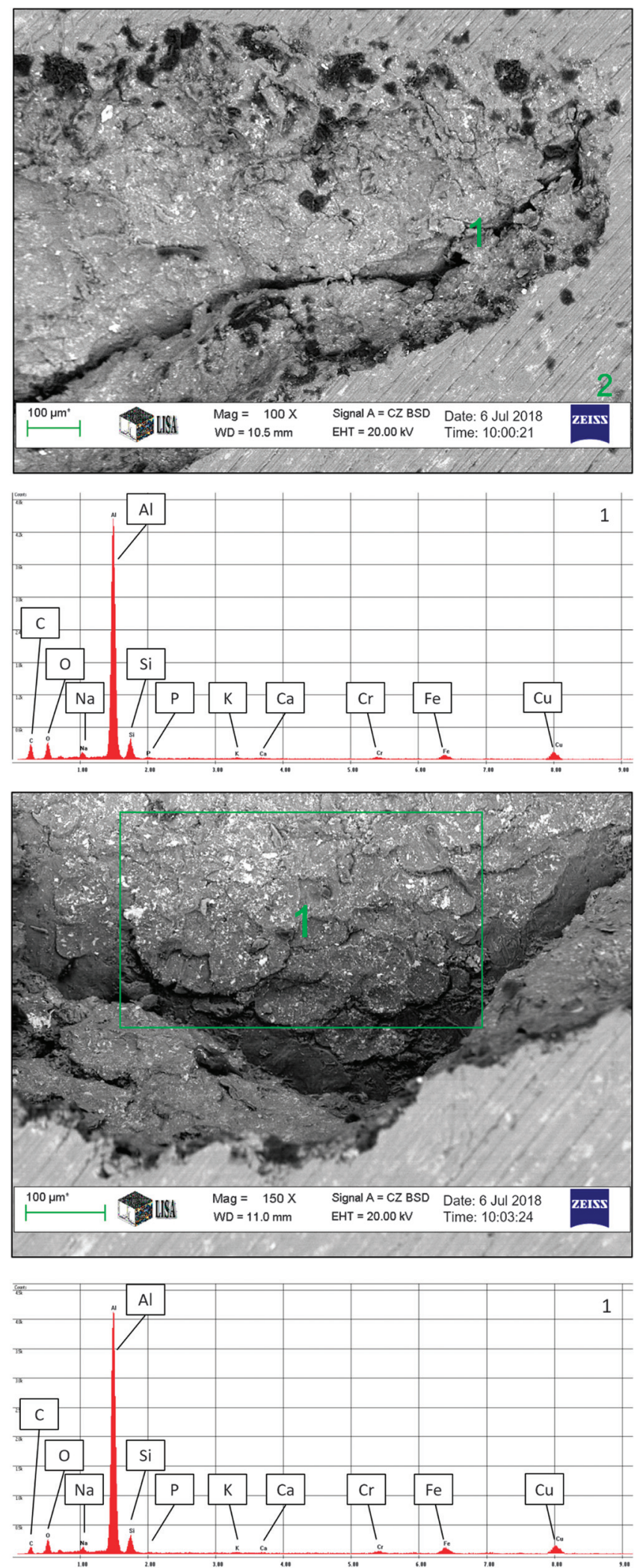

Figure 8. High oxygen content in the fracture surface by SEM.

\section{Conclusions}

The vacuum assisted high-pressure die casting process was used to produce the standard flat tensile specimens (ISO 6892-1:2016). The $\mathrm{AlSi}_{9} \mathrm{Cu}_{3}(\mathrm{Fe})$ die casting alloy was cast on atmospheric and 3 different absolute pressures of 170 mbar, 90 mbar and 70 mbar. The cast components X-ray results demonstrate that the vacuum-assisted die casting reduces the amount of entrapped air or gas in the die cavity and increased the tensile strength and elongation at the fracture. The volume of gas porosity was significantly reduced, and the size and dispersion of the porosity were improved. Based on the data presented in the study, the porosity reduced from $1.10 \%$ at an atmospheric level to $0.47 \%$ at 70 mbar, this corresponds to $57 \%$ reduction. The boundary condition of the present investigation is the porosity content higher than $0.40 \%$ and lower than $1.10 \%(0.4 \%<$ porosity $\%$ $<1.1 \%$ ). 
The effect of vacuum assist in the range of 70-90 mbar shows a significant increase in strength values. The previous linear trend shows a strong change. The mechanical properties of the vacuum-assisted castings at 70 mbar compared to the atmospheric casting shows $10 \%$ increasing, as-cast, and natural-aged conditions. The proof strength $R_{\mathrm{p} 0.2}$ increased from 159.2 $\mathrm{MPa}$ to $170.3 \mathrm{MPa}$, which is a $7 \%$ improvement. The ultimate tensile strength $R_{\mathrm{m}}$ increased from 271.6 MPa to $299.8 \mathrm{MPa}$, which corresponds to a $10 \%$ improvement. The elongation $A_{5 \%}$ increased from $1.66 \%$ to $2.49 \%$, which proves a $50 \%$ improvement.

Open Access. This is an open-access article distributed under the terms of the Creative Commons Attribution-NonCommercial 4.0 International License (https://creativecommons.org/licenses/ by-nc/4.0/), which permits unrestricted use, distribution, and reproduction in any medium for non-commercial purposes, provided the original author and source are credited, a link to the CC License is provided, and changes - if any - are indicated.

\section{References}

1. NADCA; Introduction to die casting NADCA, Arlington Heights, Illinois, 2007, 2. Chapter.

2. Chakrabarti, A. K. Casting technology and cast alloys Prentice-Hall of India, New Delhi, 2005, 11. Chapter.

3. Xixi, D.; Hailin, Y.; Xiangzhen, Z.; Shouxun, J. J. Alloys Compd. 2018 , 773, 86-96.

4. ÖGI; HPDC-technology Austrian Cooperative Research Leoben, 2016, 2. Chapter.

5. Zyska, A.; Konopka, Z.; Lagiewka, M.; Nadolski, M., Porosity of Castings Procedure by the Vacuum Assisted Pressure Die Casting Method Foundry Engineering 2015, 1, pp. 125-130.

6. Lia, X.; Xiong, S. M.; Guo, Z. J. Mater. Process. Technol. 2016, 1-7.

7. Wen-bo, Y.; Zi-hao, Y.; Zhi-peng, G.; Shou-mei, X.; Characterization of A390 aluminum alloy procedure at different slow shot speeds using vacuum assisted high pressure die casting Transactions of Nonferrous Metals Society of China 2017. 27/12. pp. 2529-2538.

8. Niu, X. P.; Hu, B. B.; Pinwill, I.; Li, H. J. Mater. Process. Technol. 2000, 105, 119-127.

9. John Campbell, Castings, Butterworth-Heinemann, Oxford, 2003, 6-7. Chapter

10. Dr.-Ing. Werner Hesse; Key to Aluminium Alloys Aluminium-Verlag Düsseldorf, 2008. 5. Chapter
11. ISO 6892-1:2016: Metallic materials - Tensile testing - Part1; Method of test at room temperature, 2016.

12. BN-75/4051-10: Porosity of Casting by hydrostatic weighing, 1975

13. Pratten, N. A. J. Mater. Sci. 1981, 16, 1737-1747.

14. Shiwei, Z.; Kun, S.; Feng, H.; Fan, Z. Vacuum, 2017, 145, 203-208.

15. Hayu, R.; Sutanto, H.; Ismail, Z. Measurement, 2019. 131, 120-124.

16. EN 1706:2013-12: Aluminium and aluminium alloys - Castings: Chemical composition and mechanical properties, 2013.

17. ITS-90 Density of Water Formulation for Volumetric Standards Calibration J. Res. Natl. Inst. Stand. Technol. Volume 97, Number 3, MayJune 1992, pp. 336-340.

18. Maierhofer, C.; Myrach, P.; Röllig, M.; Jonietz, F.; Illerhaus, B.; Meinel, D.; Richter, U.; Miksche, R. Characterization of Pores in High Pressure Die Cast Aluminum Using Active Thermography and Computed Tomography $42^{\text {nd }}$ Annual Review of Progress in Quantitative Nondestructive Evaluation; 2016, pp. 1-8.

19. Rotella, A.; Nadot, Y.; Piellard, M.; Augustin, R.; Fleuriot, M. Int. J. Fatigue 2018, 114, 177-188.

20. ASTM E505-15: Standard Reference Radiographs for Inspection of Aluminum and Magnesium Die Castings, 2015.

21. Richter, U.; Arendholz, S.; Miksche, R. R.; Rölling, M.; Maierhofer, C.; Eigenfeld, K. Int. Foundry Res. 2015, 1, 14-23.

22. Niklas, A.; Bakedano, A.; Orden, S.; Silva, M.da; Nogués, E.; Fernández-Calco, A. I. Mater. Today Proc., 2015, 2, 4931-4938.

23. Wicke, M.; Brueckner-Foit, A.; Kristen, T.; Zimmermann, M.; Buelbuel, F.; Christ, H.-J. Int. J. Fatigue 2018, 113, 87-98.

24. Azizi, A. Eng. Sci. Technol. Int J. 2015, 18, 278-285.

25. Siot, A.; Longuet, C.; Léger, R.; Otazaghine, B.; Lenny, P.; CariBretelle, A.-S.; Azéma, N. Polymer Testing 2018, 70, 92-101.

26. Hanxue, C.; Mengyao, H.; Chao, S.; Peng, L. Vacuum 2017, 146, 278-281.

27. Hu, X. G.; Zhu, Q.; Midson, S. P.; Atkinson, H. V.; Dong, H. B.; Zhang, Z.; Kang, Y. L. Acta Mater. 2017, 124, 446-455.

28. Mingfan, Q.; Yonglin, K.; Wenchuan, T.; Quanquan, Q.; Baoshun, L. Mater. Lett. 2018, 213, 378-382.

29. Qiyao, H.; Haidong, Z.; Fangdong, L. J. Mater. Sci. Eng. A 2017, 680, 270-277.

30. Bin, D.; Danyu, J.; Jianghong, G. J. Eur. Ceram. Soc. 2018, 38, 2234-2242. 31. Shevidi, A. H.; Taghiabadi, R.; Razaghian, A. Trans. Nonferrous Met. Soc. China 2018, 28, 20-29.

32. Santosh, M. V.; Suresh, K. R.; Kiran Aithal, S. Mater. Today Proc. 2017, 4, 10987-10993.

33. Bangyikhan, K., Effect of Oxide film, Fe-rich phase, Porosity and their Interactions on Tensile Properties of Cast Al-Si-Mg Alloys PhD thesis of the Faculty of Engineering of The University of Birmingham 2005.

34. Jiles, D. C., Introduction to the Principles of Materials Evaluation, Wolfson Center for Magnetic, Institute for Advanced Materials and Energy Systems, Cardiff University, U. K., 2007, 6. Chapter.

35. Campbell, J.; Cao, X. Oxide inclusion defects in Al-Si-Mg cast alloys Canadian Metallurgical Quarterly, 2005, 435-447.

36. Lijie, Z.; Bing, Y.; Jian, F.; Xiangyang, K.; Haiyan, J.; Wenjiang, D. J. Mater. Sci. Technol. 2018, 34, 1222-1228. 